\title{
Automation in Marketing: A Survey
}

\author{
Aniket Singh ${ }^{1}$, Nupoor Dode ${ }^{2}$, Rohit Barve ${ }^{3}$ \\ ${ }^{1}$ (Information Technology, Vidyalankar Institute of Technology, Mumbai \\ Email: bruces1998@gmail.com ) \\ ${ }^{2}$ (Information Technology, Vidyalankar Institute of Technology, Mumbai \\ Email: nupoordode@gmail.com) \\ ${ }^{3}$ (Information Technology, Vidyalankar Institute of Technology, Mumbai \\ Email: rohit.barve@vit.edu.in )
}

\begin{abstract}
:
In order to be able to face competition, thriving corporations have to be compelled to maintain an awfully smart relationship with their existing customers and additionally to be able to anticipate their future wants. Thus, corporations do not target customers as teams, however they're attempting to focus on them as individuals. However, to be able to use this information, corporations have to be compelled to use promoting automation tools. Marketing Automation was an idea first introduced in 2001 by John D.C. Little in his presentation at the 5th Invitational Choice Symposium UC Berkeley 2001. This survey paper assesses prominent research on Marketing Automation and suggests how it can be modified to adapt to the current marketing scenario.
\end{abstract}

\section{Keywords - Marketing Automation, Customer Relationship Management (CRMS), Automation, Machine Learning, Simulation, Marketing Simulation, Little's Framework for Marketing Automation.}

\section{INTRODUCTION}

The U.S. Small Business Administration recommends spending, "7 to 8 percent of your gross revenue for marketing and advertising if you're doing less than $\$ 5$ million a year in sales and your net profit margin - after all expenses - is in the 10 percent to 12 percent range". This in itself highlights how crucial Marketing is when it comes to gaining the attention of prospective consumers and clients, developing products or service demand and turning those prospective consumers into customers. When the importance of marketing is understood, one can use it to promote the ongoing transition of your services and products to the consumer; this can create success in businesses.

\section{MARKETING AUTOMATION}

One of the earliest definitions of marketing automation was given by Little (2001) as "the automated marketing decision support on the internet". More recently Heimbach et all (2015) defined it as "an ideology that uses databases to further execute automated communications in customer interactions"

Our definition: Marketing automation refers to use of historical customer data and technologies designed for businesses to more effectively market on multiple channels online and automate recurring marketing tasks. It acts as a decision support system for marketing teams of organizations.

Some of the aims of introducing automation in marketing were:

- Putting the "One Marketing Campaign fits all" mentality behind and Offer a more personalized experience to customers that caters to their interests.

-Making Sales and Marketing teams work together for a better customer experience. - Converting Leads 
and prospects into customers and expanding the customer lifecycle using Customer Relationship Management Systems (CRMS).

\section{CUSTOMER RELATIONSHIP MANAGEMENT SYSTEM (CRMS)}

Marketing Automation is intended to work hand in hand with Customer Relationship Management Systems. According to Parvatiyar and Sheth (2001), "customer relationship management is a comprehensive strategy and process of acquiring, retaining, and partnering with selective customers to create superior value for the company and the customer".

Our definition: Customer Relationship Management Systems offer a set of tools that aid businesses in better utilizing and managing customer data so as to continuously engage their customers and ensure a high repeat rate. It manages an organization's relationship with its customers and future customers.

\section{LITTLE'S FRAMEWORK FOR MARKETING AUTOMATION}

John D.C. Little in his presentation (2001) suggested a 5 level Framework marketing automation. This has been one of the earliest benchmarks of this field. This framework has been extensively used by organizations to design their marketing strategies.

Heimbach (2015) aptly summarized Little's framework as "evaluate the status quo situation (data analysis), derive objectives that can be fulfilled, define a set of (automated) actions to be undertaken, implement them, measure the outcome and if necessary, adapt the action plan."

The following are the 5 levels of Little's Framework for marketing automation:

(1) Data Inputs

(2) Real time decision rules.

(3) Updating decision rules.

(4) Feedback to site management.

(5) Strategy Choice

\section{A. Data Inputs}

Customer data and its management is an important step in marketing automation as it helps us take data driven decisions for customers. It is essential that we have historical customer data so as to design campaigns that are targeted, segmented and personalized. These data streams can be collected from sources as:

1. Sales data

2. Browsing Data

3. Survey Data from customer

4. Customer Service Data

5. Advertising Data

6. Web Analytics Data

\section{B. Real time decision rules}

Every customer needs to be given a personalized treatment based on their past behaviors and this where Real Time Decision Rules come into fray. Decisions like price of a product, promotional offers, content and look of the website needs to be personalized for every customer to gain maximum customer trust and all these decisions are needed to be taken at real time based on predefined rules.

\section{Updating decision rules}

Decision Rules based on older and outdated data might result in an unsatisfactory performance of our marketing model. Hence, it is necessary that the Decision Rule constantly evolves and parameters are further fine-tuned as we get access to more historical Data to further enhance Customer satisfaction. To summarize, this level tries to automate the learning process itself.

\section{Feedback to Site Management}

Customer response will also play a pivotal role in finding out how the formulated decision rules are performing. This level includes monitoring customer response to conduct performance analysis and examine trends. This can be beneficial for quality control and further optimization of decision rules. Through this feedback, businesses may also be able to observe changes in the market early on and prepare accordingly. 


\section{E. Strategy Choice}

At this level, businesses can focus on their strategy development and segment targeting based on evidence provided by historical data and customer behavior.

\section{FUTURE SCOPE AND CONCLUSIONS}

Marketing automation is one of the first steps towards offering a personalized experience to customers. Little's Framework provides a detailed and systematic layout for best implementing automation in marketing. The five-level architecture efficiently covers all the major aspects of an automated marketing workflow ensuring customer satisfaction.

However, tweaks should be made in this framework to adapt to the changes that have come with the advent of the digital age. With multiple channels to reach out to customers, be it through emails, social media or digital advertising; businesses now also have to make the choice of which of these platforms to use and how to use them to reach out to as many prospects and customers as possible.

So far, historic data and user inputs only play a role in finding out customer interests and personalizing their experience. However, this data can also be used towards figuring out which marketing channel will give out the best ROI. This can be done by using available data to produce simulations.

Simulation offers a powerful, evidence-based approach to decision-making. Through simulation, we can generate a virtual representation of the real world, and test the impact of different 'what-if' scenarios, and find an approach that delivers the best results.

With the rise of statistical training techniques and data abundance, we can now create data models that can use historical data and past behaviors to simulate how future actions might take course. Based on past marketing results we can generate the rules that governed it, and use these rules along with new data to infer how it might behave in the future.

Businesses can create marketing simulations for each of the different available channels, and then based on their results select a marketing strategy that is the best suitable. After going through all the simulations and analyzing all the scenarios in different channels, businesses can make an informed decision about their marketing workflow that will produce maximum ROI.

This inference-based approach using historical data would help businesses better channelize their time and resources.

This method of using simulations in marketing might help businesses use their customer data not only during the mid and post marketing phase, but also during the pre-marketing phase i.e., to help marketing teams of businesses in making important decisions and devising marketing strategies. If we had to inculcate this idea with Little's framework for marketing automation, we might introduce a new level between levels 1 and 2 where we are carrying out simulations once we have gathered enough data. We might call this new level as Level 1.5. This will create an all-round framework that examines customers data, aids in finding the best way to reach out to those customers and then learns from the feedback received.

\section{REFERENCE}

[1] Little JD (2001) Marketing automation on the internet. In: UC Berkeley 5 th invit choice symp, Monterey

[2] Heimbach, Irina, Daniel S. Kostyra, and Oliver Hinz. "Marketing automation." Business \& Information Systems Engineering 57.2 (2015): 129-133.

[3] Todor, Raluca Dania. "Marketing automation." Bulletin of the Transilvania University of Brasov. Economic Sciences. Series V 9.2 (2016): 87.

[4] Świeczak, Witold. "Marketing automation processes as a way to improve contemporary marketing of a company." Marketing Instytucji Naukowych i Badawczych 3 (2013): 71-84.

[5] Parvatiyar, Atul, and Jagdish N. Sheth. Conceptual framework of customer relationship management. New Delhi, India: Tata/McGrawHill, 2001. 